\title{
A circulação das elites no império dos Bragança (1640-1808): algumas notas*
}

\author{
Nuno Gonçalo Monteiro ${ }^{* *}$
}

Este artigo pretende discutir as conexões e os equilíbrios imperiais e atlânticos da monarquia brigantina setecentista, tomando como tópicos de discussão, por um lado, algumas dimensões do vocabulário social e político e, por outro, as marcas mais salientes dos processos de circulação e estruturação das elites nesse mesmo âmbito. Entre as questões debatidas, destaca-se a da fratura identitária entre reinóis e naturais da América portuguesa no início do século XIX.

Palavras-chave: Colônia - Elites - Identidades

Notes on elite's circulation in the Bragança Empire (1640-1808)

The aim of this article is to discuss the imperial and Atlantic connections and balance in the monarchy of the Bragança dynasty in the XVIII century focusing, on one side, some dimensions of the social and political vocabulary and, on the other, the outstanding processes of circulation and formation of the elite groups. One of the major issues discussed is the identity fractures between the European and the American born social actors in the beginning of the XIX century.

Keywords: Colony - Elites - Identities

La circulation des élites pendant l'empire des Bragança (1640-1808): quelques notes

Cet article cherche a discuter les connexions et les équilibres impériaux et atlantiques de la monarchie bragantine du $17^{\mathrm{e}}$ Siècle en prenant comme points de discussion,

${ }^{*}$ Artigo recebido e aprovado para publicação em junho de 2009.

** Professor do Instituto de Ciências Sociais da Universidade de Lisboa. E-mail: nuno.monteiro@ics.ul.pt. 
d'une part quelques dimensions du vocabulaire social et politique, et de l'autre, les marques les plus frappantes des processus de circulation et de structuration des élites dans ce même environnement. Parmi les questions débattues, ressort la fracture identitaire entre les natifs du Royaume et les naturels de l'Amérique portugaise au début du XIX"e Siècle.

Mots-Clés: Colonie - Elites - Identité

\section{Introdução}

O encontro do autor destas linhas com Maria de Fátima Gouvêa e outros historiadores brasileiros, há mais de uma década, marcou uma viragem nas suas pesquisas e uma reorientação das suas agendas de trabalho. A pertinência de introduzir uma referência deste tipo decorre do fato de as trajetórias de investigação de cada um constituírem um marco incontornável para quem procura entender o que vai produzindo. É certo que, ao mesmo tempo, podem configurar-se como uma fonte potencial de equívocos. A aproximação entre as historiografias portuguesas e brasileiras na última década representou, para muitos, um momento relevante na sua produção intelectual. No entanto, se os elos assim criados geraram novas interrogações, interesses e projetos, muitos dos quais comuns, todos eles naturalmente marcados pelos seus percursos anteriores, não se infere daí que cada um prosseguiu um ponto de vista nacional na sua pesquisa. No caso, não parece que exista evidentemente um preconceito comum dos historiadores "portugueses" associado à legitimação da sua identidade nacional e do respectivo passado colonial. ${ }^{1}$ Sugestão tanto mais insidiosa quanto a crítica ativa do nacionalismo imperialista português foi parte integrante da formação de grande parte dos historiadores que iniciaram a sua aprendizagem nos anos setenta. No mesmo sentido, não parece que exista um ponto de vista "brasileiro" único sobre o passado "colonial", como os debates recentes têm exuberantemente mostrado.

Dito isto, num cenário internacional no qual se multiplicam as propostas alternativas para identificar os objetos de pesquisa que abrangem os passados coloniais, desde a "história global" aos "estudos imperiais e coloniais",

${ }^{1}$ Cf. Fernando A. Novais, Aproximações. Estudos de História e Historiografia, São Paulo, CosacNaif, 2005, p. 369-373. 
passando pelas histórias "cruzadas" ou "conectadas", ${ }^{2}$ importa precisar alguns dos pontos de interseção dos nossos percursos de pesquisa. Como aconteceu com outros, o meu lugar de partida, no que a esta matéria importa, foi a história da monarquia portuguesa e das suas elites centrais e locais. Se esse foi o elo essencial, certo é que o império se atravessou nos destinos daqueles que estudei, tal como as analogias institucionais se foram impondo para quem trabalhava com grupos com um similar enquadramento, como era o caso das nobrezas locais do reino e das conquistas. $\mathrm{O}$ meu percurso cruzou-se assim com aqueles que estudavam as elites da América portuguesa, os seus processos de estruturação e de acumulação, com aqueles que se debruçavam sobre os complexos mecanismos de poder em cada um dos cenários da América portuguesa, e ainda com os que, como foi o caso particular de Fátima Gouvêa, se preocupavam com o estabelecimento de conexões imperiais, que envolviam em teias múltiplas atores com as mais diversas proveniências sociais e geográficas. ${ }^{3}$

Naturalmente, não haverá concordância em todos os trilhos traçados. Mas eles implicavam em todo o caso o reconhecimento de um marco político e institucional que configurava uma boa parte das teias estabelecidas: a monarquia portuguesa, em cujo relançamento pós 1640 as elites radicadas no Brasil tinham tido um papel decisivo e largamente autônomo - um marco que também condicionava os parâmetros de muitos daqueles percursos que se desenvolviam sem a sua intervenção direta, mas de modo algum à sua margem. Não significa, evidentemente, que não existiam outras e tão importantes histórias fora desses parâmetros. ${ }^{4}$ Foi esse, no entanto, o ponto de contato que se estabeleceu.

${ }^{2}$ Cf., entre muito outros, Jean-Fréderic Schaub, “La catégorie ‘études coloniales’ est-elle indispensable?”, Annales, Histoire, Sciences Sociales, n. 3, 2008, p.625-646.

${ }^{3}$ Cf., entre muito outros estudos, Maria de Fátima Gouvêa, "Poder político e administração na formação do complexo atlântico português (1645-1808)", in: J. Fragoso, M ${ }^{\mathrm{a}}$ F. Bicalho e M. F . Gouvêa (org.), O Antigo Regime nos Trópicos. A dinâmica imperial portuguesa (séc.s XVI-XVIII), Rio de Janeiro, Civilização Brasileira, 2001, p. 285-315; idem, Gabriel A. Frazão e Marília N. Nogueira, "Redes de poder e conhecimento na governação do império português, séculos XVI e XVII", Topoi, Rio de Janeiro, v. 5, n. 8, p. 96-137, 2004; idem, "Conexões imperiais: oficiais régios no Brasile Angola (c. 1680-1730)", in: Maria Fernanda B. Bicalho e Vera L. A. Ferlini (org.), Modos de governar. Idéias e práticas no império português, séculos XVI-XIX, São Paulo, Alameda, 2005, p. 179-197.

${ }^{4}$ Jorge Flores sublinhou que os nossos trabalhos "constituem sobretudo uma história das elites luso-brasileiras e não tanto uma verdadeira história social do Brasil colonial ou do Atlântico Sul” (“Expansão portuguesa, expansões europeias e mundos não-europeus na época moderna”, Ler História, n. 50, 2006, p.31-32). Observação em larga medida justa, mas evidentemente redundante. Desde logo, porque foi esse o objeto de investigação que se definiu, o que não implica reputálo, como se disse, mais relevante do que outros, designadamente, do que o estudo da maioria da população afro-descendente. De seguida, porque o fato das elites serem, eventualmente, "lusobrasileiras”, não deixa de constituir um ponto de interrogação, que não pode ser respondido à margem das histórias sociais e institucionais globais dos vários espaços estudados. 
Situar o campo das interrogações nos marcos da monarquia portuguesa dos Bragança tem as suas virtualidades e as suas limitações. Desde logo implica reconhecer a existência de um centro político, institucional e simbólico, e avaliar a eficácia e as restrições da sua capacidade para configurar comportamentos. De algum modo, pode sujeitar-se às críticas que se fazem à história imperial comparada. ${ }^{5}$ Mas ajuda, certamente, a perceber algumas especificidades pertinentes, como as que decorrem da comparação entre os processos de formação e de construção das identidades sociais das elites nos diversos contextos ibero-americanos; ou a formular interrogações acerca do que distinguia as elites e as instituições locais na sua relação com o centro na América e no reino. Afinal, uma questão cuja resposta é menos evidente do que pode parecer num primeiro relance.

Por diversos caminhos, os vínculos estreitos estabelecidos no contexto institucional referido conduziram alguns de nós a falar numa monarquia pluricontinental. ${ }^{6}$ Os equilíbrios institucionais, as conexões financeiras, os estreitos circuitos de circulação das elites, os fluxos migratórios, são apenas alguns dos elementos que fazem com que se não possa considerar o império, sobretudo atlântico, um mero apêndice da monarquia setecentista portuguesa. Para a sua discussão iremos invocar sucessivamente dois tópicos. Sem nenhuma pretensão à exaustividade, antes com o objetivo de esboçar problemas.

\section{Ovocabulário e as identidades sociais e políticas}

A evolução historiográfica das últimas décadas, desde o chamado "linguistic turn" até à voga da "história conceitual", impôs aos pesquisadores uma atenção renovada aos usos passados e presentes das palavras. De resto, essa viragem tem tido uma ampla e diversificada expressão no campo linguístico aqui considerado. Apesar disso, porém, há ainda um terreno de pesquisa muito vasto por desbravar.

\footnotetext{
${ }^{5}$ Cf. Jorge Flores, op. cit., p.32-33.

${ }^{6}$ Expressão discutível, cuja semântica pode invocar perspectivas ideológicas pretéritas que estão nos antípodas do que se pretende destacar, mas que utilizamos já em Nuno G. Monteiro, "Governadores e capitães-mores do império atlântico português no século XVIII", in: Maria Fernanda B. Bicalho e Vera L. A. Ferlini (org.), Modos de governar, op. cit., p. 96, e que foi usada também em João Fragoso e Maria de Fátima Silva Gouvêa, recensão a F. Bethencourt and Diogo Ramada Curto, “Portuguese Oceanic Expansion, 1400-1800”, e-Journal on Portuguese History, v. 5, n. 2, Winter 2007.
} 
Para além de vocábulos como América, Brasil ou brasileiro, em parte já pesquisados, ${ }^{7}$ e que abrangem também a discussão sobre a existência ou não de uma identidade comum aos habitantes das díspares capitanias brasileiras, gostaria aqui de relevar a importância a conferir ao estudo das utilizações da dicotomia metrópole/colônia, em larga medida ainda marcante no vocabulário dos historiadores. Se a distinção reino/conquistas parece largamente dominante no vocabulário de períodos mais remotos, designadamente no século XVII, a sua gradual depreciação esteve longe de conduzir à prevalência da outra dicotomia antes referida. A criação do Conselho Ultramarino, em 1642, terá sido um marco relevante. No decreto de criação da Secretaria de Estado dos Negócios da Marinha e do Ultramar, de 28 de julho de 1736, no entanto, fala-se tanto de "conquistas" como de "domínios", ao definir-se a área de competência da mesma. Conquistas e colônias, de resto, eram vocábulos clássicos com um uso antigo preciso e, em certa medida, alternativo. ${ }^{8}$ A gradual difusão da expressão "domínios ultramarinos" não assegurou idêntica divulgação de um vocábulo que qualificasse o centro político do império. No seu incontornável dicionário dos primórdios dos setecentos, Bluteau esclarece que metrópole se reporta à cidade sede arquidiocese, cidade mãe das outras, cidade principal; e diz claramente: "antigamente se apropriava a cidades das quais haviam saído colônias”. A difusão do termo na segunda metade do século XVIII é muito tardia e localizada, encontrando-se claramente associada à difusão do vocabulário da economia política.

Como se destaca em trabalho recente de Teresa Kirschner, era o caso de Silva Lisboa que, em 1781, se referia ao Brasil como uma colônia favorecida pela metrópole: "Em geral, colônias mais favorecidas pela metrópole não são fáceis de achar como a nossa". ${ }^{9}$ Foi só no contexto do vintismo que a sua postura ${ }^{7}$ Cf., entre muitos outros: João Paulo G. Pimenta, "Portugueses, americanos, brasileiros: identidades políticas na crise do Antigo Regime luso-americano", Almanack brasiliense, n. 3, 2006, p. 69-80; Luiz Felipe de Alencastro, "Le versant brésilien de L’Antlique-Sud: 15501850", Annales HSS, mars-avril, n. 2, 2006, p. 339-383; Istvan Jancsó, "Brasil e brasileiros - Notas sobre modelagem de significados políticos na crise do Antigo Regime português na América”, Estudos Avançados, n. 22 (62), 2008, p. 257-274.

${ }^{8}$ Segundo Rafael Bluteau, “conquista” seria “a terra conquistada”, enquanto “colônia” seria "gente que se manda para uma terra novamente descoberta ou conquistada para a povoar; a mesma terra assim povoada”. Vocabulario portuguez e latino, aulico, anatomico, comico, critico, chimico, dogmatico, dialetico, \& Autorisado com exemplos dos melhores escriptores portugueses e latinos; e offerecido a el rey D. João V, 8 vols., Coimbra, 1712-1721.

${ }^{9}$ Carta de José da Silva Lisboa a Domingos Vandelli, citada em Tereza Cristina Kirschner, "Um pouco de historiografia: a representação do passado colonial brasileiro a partir da independência”, in: Anais de História de Além Mar (no prelo). 
mudou. Mais tarde, em 1825, seria encarregado por D. Pedro I de escrever uma História do Brasil que incluísse o período da independência. O livro de Silva Lisboa, "História dos principais sucessos do império do Brasil", publicado em 1826, expressaria o imaginário político da elite promotora da independência: "O caráter do Congresso era a imobilidade em seu projeto de repor este reino no antecedente estado de colônia, perpetuando a tirania da metrópole lusitana pelo suspirado restabelecimento do monopólio do sistema colonial". ${ }^{10}$ De acordo com a mesma autora, foi essa a matriz da projeção retrospectiva da oposição metrópole/colônia que inspirou boa parte da ulterior historiografia.

Uma segunda questão em matéria de vocabulário social que gostaria de salientar, neste caso por comparação com a América espanhola, é a inexistência no contexto do Brasil colonial de uma identidade social equivalente à das elites "crioulas", intencionalmente atingidas pelas reformas bourbônicas levadas a cabo pela monarquia espanhola desde os anos sessenta do século XVIII, com o objetivo confessado de diminuir o seu peso nas instituições locais e regionais. Por tal se entende as elites locais dominantes nascidas na América, geralmente de origem europeia, que detinham um papel dirigente nessas mesmas instituições. Não havia correspondente semântico no Brasil. Segundo Bluteau, crioulo queria dizer "escravo que nasce na casa do seu senhor"; o termo "crioulo da terra" foi utilizado uma única vez no processo da inconfidência mineira e para designar um homem de cor parda. ${ }^{11}$ No mesmo contexto, o termo "mazombos", tão relevante em Pernambuco no início de setecentos para qualificar as elites locais, só aparece como uma ocorrência secundária. ${ }^{12}$

Apesar de parte da historiografia recente relativizar os seus resultados, não oferece dúvidas que na política levada a cabo pelos ministros de Carlos III pesou de forma decisiva e assumida o objetivo de "desconstrução do Estado crioulo"13 nas Américas espanholas. Pelo contrário, como notou desde há muito Stuart Schwartz, "parecia faltar às medidas de Pombal o tom especialmente anticrioulo dos esforços de Galvez na América espanhola (...) as reformas pombalinas não excluíram do governo os grupos brasileiros em posição mais elevada; tenderam, isso sim, a ampliar o seu papel". ${ }^{14}$ Haverá que perguntar

\footnotetext{
${ }^{10}$ Citado em Tereza Cristina Kirschner, op. cit.

${ }^{11}$ Cf. Roberta G. Stumpf, Filhos das Minas, americanos e portugueses: identidades coletivas na Capitania das Minas Gerais (1763-1792), dis. Mest. Mimeo., USP, 2001, p. 195.
}

${ }^{12}$ Cf. Evaldo Cabral de Mello, A Fronda dos Mazombos. Nobres contra Mascates: Pernambuco, 1666-1715, S. Paulo, Companhia das Letras, 1995, e R. Stumpf, op. cit., p.192.

${ }^{13}$ John Lynch, "El reformismo borbónico e hispanoamérica", in: Augustín Guimerá (ed.), El Reformismo borbónico, Madrid, Alianza Editorial, 1996, p. 44.

${ }^{14}$ Stuart B. Schwartz e James Lockhart, A América Latina na época colonial, Rio de Janeiro, Civilização Brasileira, 2002, p. 448-449. 
por que razão existiu tal diferença. $\mathrm{E}$ a que parece mais evidente é que, não obstante todos os esforços de uma velha tradição historiográfica brasileira para erigir a "inconfidência" mineira ou a conspiração baiana em prenúncios de uma consciência nacional, para a quase totalidade dos contemporâneos residentes da América portuguesa não existia uma fratura geral, suscetível de ser alargada a todas as capitanias, entre as elites dominantes nascidas no reino e as que tinham nascido localmente. Em síntese, não existia por volta de 1808 a percepção generalizada de uma fratura entre "crioulos" e "peninsulares", como acontecia na América espanhola. ${ }^{15}$ Esses termos nem sequer tinham um equivalente indiscutível no vocabulário português da época. As oposições que se poderiam assemelhar ("mascates"/"mazombos", "reinóis"/"brasileiros" ou "brasílicos") tinham então uma escassa difusão. Uma realidade essencial, que carece de explicação.

\section{A circulação e a estruturação das elites ${ }^{16}$}

Para explicar as diferenças referidas entre as duas monarquias ibéricas, para além de genealogias discursivas, parece legítimo invocar dimensões extratextuais. Com efeito, como já foi invocado, "em termos gerais, Brasil e Portugal permaneceram em contato mais estreito e com menos distinções entre si do que a América espanhola e Espanha". ${ }^{17}$

O peso do império nas finanças da monarquia portuguesa constituiu um traço estrutural das mesmas, de há muito conhecido. ${ }^{18}$ Desde os primórdios da época moderna, na maior parte das conjunturas, era o império que, direta ou indiretamente, sustentava a monarquia, fornecendo em regra, pelo menos,

\footnotetext{
${ }^{15}$ Fato também destacado por Robert Rowland, mas considerando a elite crioula da América espanhola fruto “da miscigenação entre colonizadores brancos e população indígena”, o que não seria um fato em regra (“A cultura brasileira e os portugueses”, in: Cristiana Bastos et al. (org.), Trânsitos coloniais: diálogos críticos luso-brasileiros, Lisboa, Imprensa de Ciências Sociais, 2002, p. 377); para um enquadramento geral da questão e um estudo de caso, cf. Margarita Eva Rodrigues Garcia, Criollismo y pátria en la Lima ilustrada (1732-1795), Buenos Aires, Miño y Dávila Editores, 2006.

${ }^{16}$ Retomam-se aqui tópicos desenvolvidos no texto "As reformas na monarquia pluricontinental portuguesa: de Pombal a D. Rodrigo", in: João Fragoso e Maria de Fátima Gouvêa (org.), O Brasil Colonial (no prelo).

${ }^{17}$ S. Schwartz e J. Lockhart, op. cit., p.450-451.

${ }^{18}$ Cf. Vitorino Magalhães Godinho, "Finanças públicas e estrutura do Estado", in: Ensaios, vol. II, Sobre História de Portugal, 2. ed., Lisboa, Ed. Sá da Costa, 1978; Fernando Tomaz, "As finanças do Estado pombalino (1762-1776)", in: Estudos e ensaios em homenagem a Vitorino Magalhães Godinho, Lisboa, Livraria Sá da Costa, 1988; e Álvaro Ferreira da Silva, "Finanças públicas", in: Pedro Lains e Álvaro Ferrreira da Silva (org.), História Económica de Portugal 1700-2000, tomo I, Lisboa, Imprensa de Ciências Sociais, 2004.
} 
metade dos seus réditos. Através das receitas das alfândegas, que raras vezes representaram menos de um quarto do total e muitas vezes se aproximaram da metade; depois, através dos vários monopólios ligados ao império; e, por fím, por via dos impostos diretos, em particular sobre metais e pedras preciosas. Embora variável ao longo do tempo e decisiva em várias conjunturas, parece certo que a dependência da monarquia espanhola das receitas do império não era tão esmagadora.

Entretanto, ao fato bem conhecido da conexão financeira, haverá agora que acrescentar outro. Em nenhum estado europeu as elites possuíam uma experiência do império comparável à portuguesa. A monarquia portuguesa tinha uma dimensão imperial única no contexto da Europa do século XVIII. Não apenas pela referida dependência financeira, mas também porque as respectivas elites tinham, quase na mesma medida em que se fecharam aos contatos culturais com outras potências do velho continente, uma experiência de circulação pelo império que não tinha paralelo na época. Acresce que os naturais do reino desempenhavam um papel sem equivalente na estruturação das elites do Brasil. Em parte, isso explicar-se-á pelo fato da população da América portuguesa ter crescido no século XVIII mais rapidamente do que na espanhola e sobretudo à conta da emigração (de europeus e, sobretudo, da forçada dos africanos) e não do crescimento natural. Mas a explicação não residirá só aí.

De entre os trajetos de circulação imperial diretamente promovida pela coroa, os governadores coloniais constituíam o elemento simbolicamente mais destacado. E a política da coroa de pôr a primeira nobreza a servir nas conquistas deu os seus frutos. Com efeito, detectamos um claro processo de aristocratização ou elitização dos critérios de recrutamento para o vice-reinado e governos das capitanias brasileiras, entre os séculos XVII e XVIII, visível quer nas principais capitanias, quer na esmagadora maioria das capitanias subordinadas. No Brasil, tomado como um todo, os descendentes de titulares da primeira nobreza de corte e de fidalguia inequívoca passam de $20 \%$ dos nomeados no século XVII para 45\% no século XVIII; nas capitanias principais, passa de $57 \%$ para $82 \%$. Em sentido inverso, verifica-se uma clara redução do número de "brasílicos" nomeados. Na América portuguesa, a porcentagem dos naturais desce de $22 \%$ no século XVII para apenas $10 \%$ no século seguinte, quando os naturais da terra representavam apenas $3 \%$ dos nomeados nas 
capitanias principais (antes alcançavam 27\%), desaparecendo nos governos da Bahia e do Rio. ${ }^{19}$

Caso único no contexto europeu, a maior parte das grandes casas aristocráticas portuguesas teve alguns dos seus membros num governo das ilhas e domínios ultramarinos. Mais da metade das 130 casas titulares que existiram em algum momento entre 1640 e 1810 teve um dos seus senhores nesses ofícios ao longo dos séculos XVII e XVIII. Mas, se considerarmos apenas as que tiveram uma existência durável, esse números sobem para mais de dois terços. E teríamos, em rigor, de acrescentar as casas da primeira nobreza que por essa via ascenderam à grandeza, recebendo título. No período considerado, não parece existir nenhuma outra elite aristocrática europeia para a qual a circulação e o desempenho de ofícios num império fora da Europa tenha tido um papel comparável. ${ }^{20} \mathrm{Na}$ monarquia espanhola, embora predominem os ibéricos, os representantes de casas nascidos com título de Grande de Espanha ocupando governos no império foram poucos no século XVIII. ${ }^{21}$

Também promovida pela coroa, a circulação da magistratura letrada tinha uma função destacada, numa monarquia na qual a partir de meados do século só existia uma única universidade, localizada no reino (Coimbra). Entre 1772 e 1826, 417 magistrados (juízes de fora, ouvidores e desembargadores) foram providos para as ilhas e o ultramar, ou seja, cerca de um quarto do total das nomeações para toda a monarquia. Parece que seria uma forma mais rápida de ascensão na carreira, pois destes, quase um terço (114) chegou a desembargador, visto que a proporção dos nomeados no reino que chegaram a tal estatuto foi mais baixa. De resto, registra-se que apenas $7 \%$ dos referidos magistrados regressaram ao reino, ${ }^{22}$ o que significa que a imensa maioria se integrou nas sociedades locais. Ao longo do século (XVIII), parece que o número de naturais do Brasil a alcançar o estatuto de desembargador foi au-

${ }^{19}$ Cf. Mafalda Soares da Cunha e Nuno G. Monteiro, "Governadores e capitães-mores do império atlântico português nos séculos XVII e XVIII", in: N. G. Monteiro, P. Cardim e M. S. da Cunha (org.), Óptima Pars. Elites Ibero-Americanas do Antigo Regime, Lisboa, Imprensa de Ciências Sociais, 2005, p. 211-214.

${ }^{20} \mathrm{Em}$ larga medida, é disso mesmo que se ocupa a Parte II do livro de Laura de Mello e Sousa, O sol e a sombra. Política e administração na América Portuguesa do século XVIII, São Paulo, Companhia das Letras, 2006.

${ }^{21}$ É o que se conclui a partir de alguma pesquisa feita com base em David Henige, Colonial Governors from the Fifteenth Century to the Present. A Comprehensive List, Madison, University of Wisconsin Press, 1970.

${ }^{22}$ Cf. José Subtil, “Os ministros do rei no poder local, ilhas e ultramar (1772-1826)”, Penélope, n. 27, 2002, p. 37-58. 
mentando. No que se refere aos desembargadores da Bahia, de 1696 a 1758, sabemos que, num universo de mais de uma centena, apenas cinco tinham nascido no Brasil. Significativamente, de entre um total de 54 desembargadores do Rio de Janeiro providos, entre 1750 e 1808, sabemos que pelo menos cerca de um terço (16) eram naturais do Brasil. ${ }^{23}$ Entretanto, importa sublinhar que na América espanhola, dotada de universidades, entre 1770 e 1810, os crioulos representavam entre $20 \%$ e $70 \%$ dos ministros das respectivas audiências. ${ }^{24}$ De resto, apesar da diminuição do número total de alunos depois das reformas pombalinas, parece que a proporção dos nascidos no Brasil que se graduaram (a maior parte em direito) na Universidade de Coimbra foi aumentando entre o início do século XVIII e o princípio do seguinte. ${ }^{25}$ A frequência da Universidade de Coimbra manteve-se elevada, como se sabe, depois de 1822, associada ao desempenho de destacadas funções na vida política da antiga colônia. ${ }^{26}$

Em regra provido também pela coroa era o clero secular. Ao nível do clero paroquial, entretanto, no primeiro terço do século XIX, cerca de três quartos dos eclesiásticos do Brasil eram naturais de lá, embora cerca de metade fossem filhos de reinóis e de mães nascidas na América portuguesa ${ }^{27}$ um dos casos indiscutíveis de um grupo dominante nascido no Brasil, embora não se possa saber exatamente desde quando. Quanto aos bispos, sabemos que no conjunto das Américas espanholas o número dos naturais aumentou muito, representando $40 \%$ em 1750, cerca de $50 \%$ em 1770 e mais de $60 \%$ em 1810 $1820 .{ }^{28}$ No Brasil, apesar de se terem juntado às dioceses já existentes (Bahia, Maranhão, Olinda e Rio), cinco novas criadas no século XVIII (Cuiabá, em Mato Grosso, Goiás e Mariana, em Minas, Pará e São Paulo), houve apenas 62 bispos nomeados entre 1701 e 1822 , e destes, apenas seis tinham nascido na América portuguesa, tendo todos sido providos depois de $1770 .^{29}$

${ }^{23}$ Cf. Stuart Schwartz, Sovereignty and Society In Colonial Brazil. The High Court of Bahia and its Judges 1609-1751, Los Angeles, University of California Press, 1973, e Arno Wehling e Maria José Wehling, Direito e Justiça no Brasil colonial. O Tribunal da Relação do Rio de Janeiro - 1751/1808, Rio de Janeiro/SãoPaulo, Editora Renovar, 2004, p. 268-269.

${ }^{24}$ Cf. Juan Carlos Caravaglia e Juan Marchena, América Latina de los orígenes al a Independência II. La sociedad colonial ibérica en el siglo XVIII, Barcelona, Crítica, 2005, p. 328-334.

${ }^{25}$ Fernando Taveira da Fonseca, "The Social and Cultural Roles of the University of Coimbra (1537-1820). Some considerations”, e-Journal on Portuguese History, v. 5, n. 1, 2007.

${ }^{26}$ Cf. José Murilo de Carvalho, A construção da ordem. A elite política imperial, Rio de Janeiro, Editora Campus, 1980.

${ }^{27}$ Cf. Guilherme Pereira das Neves, E receberá mercê: a Mesa da Consciência e Ordens e o clero secular no Brasil, 1808-1828, Rio de Janeiro, Arquivo Nacional, 1997, p. 193 e seg.

${ }^{28}$ Cf. Juan Carlos Caravaglia e Juan Marchena, América Latina..., op. cit., p. 320-328.

${ }^{29}$ Cf. José Pedro Paiva, Os Bispos de Portugal e do Império 1495-1777, Coimbra, Imprensa Universidade de Coimbra, 2006, p. 555-557 e informações generosamente fornecidas pelo autor. 
Falta-nos ainda conhecer muito sobre os segmentos médios e inferiores do exército. Mas sabemos já bastante sobre os oficiais superiores (de brigadeiro para cima), os quais eram esmagadoramente reinóis, ${ }^{30}$ ao invés do que se passava com a América hispânica.

Entretanto, às dimensões referidas, associadas à emigração promovida pela coroa, deve-se acrescentar uma outra diferença, particularmente notória no século XVIII, e que parece muito relevante: os fluxos de circulação de pessoas entre a Europa e a América eram, em termos relativos, bem mais destacados no caso português e, sobretudo, tinham um peso mais importante na estruturação das elites americanas. Por outras palavras, os naturais da península foram muito mais numerosos e marcantes na configuração dos equilíbrios de poder nos brasis, cuja população se multiplicou por dez ao longo do século XVIII, do que nas Américas espanholas.

Em favor do que antes se disse, pode-se invocar um fato que se acentua na primeira metade dos setecentos e passa geralmente desapercebido: embora a monarquia espanhola tenha perdido boa parte dos seus territórios europeus não ibéricos depois da Guerra da Sucessão, a verdade é que os volumes da emigração de ibéricos para a América espanhola foram ao longo da primeira metade do século, não só em termos relativos, mas em termos absolutos, mais reduzidos do que os de habitantes de Portugal e das ilhas Atlânticas para o Brasil no auge da explosão aurífera. ${ }^{31}$ Mesmo que não se dê crédito aos autores que afirmam que o número de emigrantes portugueses para o Brasil nos momentos altos do surto aurífero alcançou os 9 ou 10 mil por ano, ${ }^{32}$ e se situe o seu montante num máximo de 2 ou 3 mil por ano, ${ }^{33}$ tais valores superam o dos ibéricos que emigraram para a América espanhola. Com efeito, tendo em

\footnotetext{
${ }^{30}$ Ainda entre 1837 e 1850, cerca de metade dos generais do exército brasileiro tinha nascido em Portugal! Cf. Adriana Barreto de Souza, "Ao serviço de Sua Majestade: a tradição militar portuguesa na composição do generalato brasileiro (1837-50)", in: Celso Castro, V. Izecksohn e H. Kraay (org.), Nova história militar brasileira, Rio de Janeiro, Editora FGV, 2004, p. 160-163.

${ }^{31}$ Parte do que aqui se diz baseia-se em extrapolações feitas a partir de Máximo Livi Bacci, "500 anos de demografia brasileira: uma resenha", Revista Brasileira de Estudos de População, v. 19, n. 1, jan./jun. 2002; no entanto, algumas das explicações sugeridas pelo autor (cf. p. 142) situam-se nos antípodas daquelas que aqui se fornecem.

${ }^{32}$ Números propostos por Vitorino Magalhães Godinho, "L'emigration portugaise (XVe-XVIIIe siécles)”, Revista de História Económica e Social, n. 1, 1978, p. 5-32, e, retomados, entre muitos outros, por Robert Rowland, “O problema da emigração: dinâmicas e modelos”, in: Francisco Bethencourt e Chauduri, Kirti (dir.), História da Expansão Portuguesa, v. 4, Lisboa, Círculo dos Leitores, 1998, p. 305.

${ }^{33}$ Livi Bacci, op. cit.; A. J. R. Russel Wood, Um mundo em movimento: os portugueses na África, Ásia e América (1415-1808), Lisboa, Difel, 1998, p. 98, apresenta valores um pouco mais elevados.
} 
conta apenas a emigração legal, "calcula-se que 53 mil espanhóis migraram para a América durante o século XVIII (...) uma média de apenas 500 por ano". ${ }^{34}$ Se se aceitar que a emigração ilegal duplicou esses números, então, na melhor das hipóteses, o número de emigrantes alcançaria ao longo do século XVIII os $100.000 .{ }^{35}$ Ora, só entre 1700 e 1750 terão emigrado para o Brasil, no mínimo, uns 100 mil portugueses (há quem pense que foram muitos mais...), o que é também bastante superior à emigração das ilhas britânicas para as suas colônias da América do Norte, no mesmo intervalo temporal. ${ }^{36}$ De resto, os maiores volumes de emigração da península para a América espanhola registraram-se no século XVI, os das ilhas britânicas para a América inglesa no século XVII, e os de Portugal para o Brasil no século XVIII. Uma diferença flagrante, portanto.

No início do século XIX (cerca de 1800), a população espanhola seria de 11,5 milhões de habitantes, 3 milhões a de Portugal, a da América espanhola 13,5 milhões, contra 3,3 milhões no Brasil. Mas, apesar de o número de brancos no Brasil ser inferior ao da América espanhola, estes representavam uma parcela proporcionalmente mais elevada da população no Brasil e resultavam de volumes acumulados de emigração europeia equivalentes (600 a 800 mil), aliás, também idênticos aos dos EUA. Não restam dúvidas que o esforço emigratório de Portugal (relação população de origem/emigração) foi cerca de três vezes superior ao de qualquer outra potência europeia, tal como sugere Livi Bacci. ${ }^{37}$ É certo que os números não se baseiam em fontes seguras e, sobretudo, que não se contabilizam as taxas de retorno que eram, certamente, muito elevadas. Mas as grandes diferenças não deixam de se realçar, apesar disso.

Acontece que, embora muito falte ainda por conhecer e se corra o risco de tirar conclusões precipitadas, importa destacar que o que se revela mais impressionante não são apenas os volumes da emigração portuguesa para o Brasil, mas sobretudo a natureza desta e o papel aparentemente estrutural que

\footnotetext{
${ }^{34}$ Nicolas Sánchez-Albornoz, "A população da América Espanhola Colonial”, in: L. Brethel (org.), História da Amércia Latina, v. II, São Paulo, EDUSP, 2004, p. 52; os mesmos valores são apresentados por John Lynch, op. cit., p. 39.

${ }^{35}$ Cf. Carlos Martínez Shaw, La emigración española a América, Gíjon, Archivo de Indianos, 1994, p. 167 e 249.

${ }^{36}$ Cf. James Horn, "British Diaspora: Emigrants from Britain, 1680-1815”, in: P. J. Marshal (ed.), The Oxford History of the British Empire - The Eighteenth Century, Oxford, Oxford University Press, 2001, p. 32; no terceiro quartel dos setecentos, no entanto, a referida emigração britânica foi superior (perto de 150.000 pessoas em 25 anos).
}

${ }^{37}$ Op. cit., p. 146. 
ela adquiriu na configuração das próprias sociedades da América portuguesa. Apesar da emigração espanhola se ter modificado no século XVIII, passando a ter origens geograficamente mais diversificadas, o primeiro lugar de partida continuava a ser a Andaluzia (com cerca de um quarto dos emigrantes legais) e os criados (com cerca de $37 \%$ do total) eram o grupo mais numeroso; é certo que as províncias do Norte (bascos, galegos, cantábrios e asturianos) forneciam agora mais gente (somadas, cerca de um quarto do total), que os emigrantes destas zonas eram esmagadoramente masculinos e que ofereciam a base de recrutamento da maioria dos negociantes de cidades como a do México e a de Buenos Aires. Só que este padrão, semelhante ao português, não era nem universal, nem sequer dominante no conjunto da América espanhola. ${ }^{38} \mathrm{Com}$ efeito, a emigração "espontânea" portuguesa (isto é, não organizada pela coroa) tinha sobretudo origem no Norte de Portugal, particularmente no Minho (que fornecia em norma mais de metade dos migrantes), seguida pelas ilhas, e por zonas do Centro do reino e de Lisboa (do Sul, outrora tão importante, agora quase nada). Era uma emigração majoritariamente jovem, masculina, e, ao que tudo indica, alfabetizada, que se inseria em grande medida dentro de uma lógica de expulsão de filhos excedentários de grupos domésticos de lavradores razoavelmente abastados do Nordeste, a zona agrícola mais rica e densamente povoada de Portugal, e também de filhos de artesãos; $;^{39}$ uma emigração de remediados, portanto, dotados de dois capitais extremamente valiosos: saber ler e escrever, num reino esmagadoramente analfabeto, e um espectro de relações que lhes garantiam uma colocação conveniente no local quase sempre urbano de destino.

Com efeito, substituindo desde, pelo menos, finais dos seiscentos os grupos de cristãos novos, e contando com a proteção de redes familiares e locais bem consolidadas, era por essa via que estruturavam os grupos mercantis das várias praças do Brasil e da região das Minas. ${ }^{40}$ Tudo parece sugerir

\footnotetext{
${ }^{38}$ Cf. Carlos Martinez Shaw, op. cit., p. 178-194.

${ }^{39} \mathrm{Cf}$. os trabalhos decisivos de Jorge Pedreira, entre os quais "O Brasil, fronteira de Portugal. Negócio, emigração e mobilidade social (séculos XVIIe XVIII)”, in: Mafalda Soares da Cunha (coord.), Do Brasil à Metrópole efeitos sociais (séculos XVII-XVIII), Évora, Universidade de Évora, 2001, p.47-72. Deve-se sublinhar que a articulação entre emigração e mundo rural no Minho se apoia numa ampla bibliografia sobre este, que não cabe aqui citar.

${ }^{40} \mathrm{Cf}$. para a Bahia os dados retomados por Jorge Pedreira e para as outras capitanias a bibliografia adiante citada. Para Minas, cf. Junia Ferreira Furtado, Homens de Negócio: a interiorização da metrópole e do comércio nas Minas setecentistas, 2. ed., São Paulo, Hucitec, 2006, p. 154; e Carla M. C. Almeida, "Homens ricos em Minas Colonial", in: Maria Fernanda Bicalho e Vera L. A. Ferlini, Modos de Governar, op.cit., p.370.
} 
que no Brasil, como já foi assinalado, "no século XVIII (...) a classe mercantil permanecia essencialmente europeia" (de nascimento). ${ }^{41}$ É certo que as elites mercantis têm sido renovadamente estudadas nos últimos anos e que é talvez estultícia pretender apresentar uma breve síntese sobre o tema. Mas tinham uma origem geográfica e social semelhante no Rio, na Bahia, no Recife, em São Paulo, nas várias povoações de Minas ou no Rio Grande do Sul, ${ }^{42}$ embora as modalidades e a cronologia da sua afirmação como grupo autônomo, da sua aproximação ou afastamento das elites terratenentes, e, por fim, do seu maior ou menor acesso à elite camarária (aquilo que em sentido restrito configurava propriamente a "nobreza da terra" em cada município da monarquia portuguesa), têm constituído objeto de investigações múltiplas. Apesar disso, não restam dúvidas sobre o laço umbilical existente entre a emigração nortenha portuguesa e os grupos mercantis brasileiros, o qual se prolonga bem depois de $1822 .{ }^{43}$

Como tem sido bem destacado pela bibliografia recente, as câmaras constituíam o principal instrumento de integração política da colônia e das suas elites no espaço imperial. ${ }^{44} \mathrm{Na}$ primeira metade do século XVIII, houve recorrentes tensões e conflitos (como em Pernambuco e no Rio de Janeiro) entre as elites agrárias estabelecidas e os grupos mercantis, procurando as primeiras impedir o ingresso dos segundos nos ofícios camarários. Note-se, entretanto, que o fato de não se venderem ofícios de vereador na monarquia portuguesa, ao contrário do que acontecia com os regedores na monarquia espanhola e seu império, fazia com que os mesmo fossem sempre eletivos, encontrando-se à partida mais disponíveis, o que acabou por facilitar o acesso dos reinóis aos senados municipais na América portuguesa.

\footnotetext{
${ }^{41}$ Stuart Schwartz, Da América portuguesa ao Brasil, Lisboa, Difel, 2003, p. 228-230.

${ }^{42} \mathrm{Cf}$. bibliografia adiante citada e Helen Osório, O império português no Sul da América. Estancieiros, lavradores e comerciantes. Rio Grande do Sul, Porto Alegre, Editora UFRGS, 2007, p.277 e seg., maxim. p.283.

${ }^{43}$ Cf. os dados apresentado para 1823-1834 em Gladys Sabina Ribeiro, A Liberdade em Construção. Identidade nacional e conflitos antilusitanos no Primeiro Reinado, Rio de Janeiro, FAPERJ/Relume Dumará, 2002, p.181 e seg., que confirmam o predomínio dos jovens solteiros, minhotos, alfabetizados e destinados a serem recebidos por comerciantes já estabelecidos no Rio entre as centenas de emigrantes portugueses chegados com passaporte nos anos posteriores à independência.

${ }^{44}$ Na esteira das sugestões Charles Boxer, Portuguese Society in the Tropics. The Municipal Councils of Goa, Macao, Bahia, and Luanda, Madison, University of Wisconsin Press, 1965, o tema tem sido amplamante reafirmado, em particular por Maria Fernanda Bicalho. Cf, entre outros, idem, "As Câmaras ultramarinas e o governo do Império", in: J. Fragoso, M. F. Bicalho e M. F. Gouvêa (org.), op. cit., 2001, p. 189-221.
} 
Ora, se a maioria dos negociantes do Brasil (mas não todos) era, ao que tudo indica, natural do norte de Portugal e disputava com as elites terratenentes o acesso às câmaras, o fato é que na segunda metade do século XVIII, em maior ou menor proporção, todos acabaram por entrar nas principais câmaras, ao contrário do que aconteceu com quase todos os municípios importantes do reino. ${ }^{45} \mathrm{O}$ caso mais emblemático é o do Rio de Janeiro, entre 1794 e 1822, cuja numerosa elite política teria raízes majoritariamente mercantis, embora os seus membros se fossem progressivamente condecorando com distinções nobilitantes; ${ }^{46}$ isto depois da forte polarização política entre conquistadores e negociantes verificada na primeira metade do século XVIII. Entre os vereadores eleitos da câmara de S. Salvador da Bahia, ao longo do século XVIII, predominaram os senhores de terras, engenhos, escravos ou gado, mas o peso dos negociantes não deixou de ser muito significativo. ${ }^{47}$ No Recife eles representavam 55\% dos homens bons da câmara, entre 1710 e 1822, embora neste caso o número de naturais do Brasil tenha ultrapassando regularmente o dos nascidos em Portugal a partir de $1760 .{ }^{48}$ Da mesma forma, na câmara de São Paulo os homens de negócio, provenientes na sua esmagadora maioria do Minho, eram já majoritários por volta de $1800 .{ }^{49}$ Também no recém criado município de Porto Alegre, as pessoas ligadas ao negócio representavam a maioria dos oficiais camarários, cuja ocupação se conhecia, ${ }^{50}$ o mesmo se verificando entre os camaristas identificados do efêmero município de Viamão

${ }^{45}$ Entre os raros municípios portugueses nos quais havia negociantes elegíveis em número apreciável estão os da Figueira da Foz (tardiamente criado em 1771) e os da Covilhã e Fundão (ligados à indústria dos lanifícios); casos absolutamente excepcionais e que não abrangiam nenhum centro urbano sede de comarca ou especialmente relevante; Cf. Nuno G. Monteiro, "Elites locais e mobilidade social em Portugal nos finais do Antigo Regime", in: Idem, Elites e Poder. Entre o Antigo Regime e o Liberalismo, $2^{\mathrm{a}}$ ed., Lisboa, Imprensa das Ciências Sociais, 2007, p. 62-64.

${ }^{46}$ Maria de Fátima Gouvêa, "Os homens da governança do Rio de Janeiro em fins do século XVIII e início do XIX”, in: O Município no Mundo Português, Funchal, Centro de Estudos de História do Atlântico, 1998, p. 545-562.

${ }^{47}$ Cf. Avanete Pereira Sousa, Poder local, cidade e actividades económicas (Bahia, século XVIII), dis. mimeo., São Paulo, USP, 2003, p. 143-145; e Idem, "Poder local e autonomia camarária no Antigo Regime: o Senado da Câmara da Bahia (século XVIII)”, in: Maria Fernanda Bicalho e Vera L. A. Ferlini, Modos de Governar..., op. cit., p. 319.

${ }^{48}$ Cf. George F. Cabral de Souza, Elite y ejercicio de poder en el Brasil colonial: la Cámara Municipal de Recife (1710-1822), diss. dout. mimeo., Salamanca, US, 2007.

${ }^{49}$ Cf. Maria Aparecida Borrego, A teia mercantil. Negócios e poderes em São Paulo colonial 1711-1765, São Paulo, diss. mimeo., 2006, p. 141-142.

${ }^{50}$ Cf. Adriano Comissoli, Os “homens bons" e a Câmara Municipal de Porto Alegre (17671808), Porto Alegre, Câmara Municipal de Porto Alegre, 2008, p. 70. 
(1763-1773), nos confins tumultuosos do Sul. ${ }^{51}$ Em conclusão, em finais do período colonial, a partir pelo menos do último terço dos setecentos, apesar da semelhança da matriz institucional, enquanto no reino, com maiores ou menores abalos, prevaleciam no governo dos respectivos municípios elites dominantemente agrárias e fidalgas, com quase total exclusão dos negociantes, mesmo dos de grosso trato; estes tinham acesso a todas as principais câmaras da América portuguesa, hegemonizando muitos deles, entre os quais o do Rio de Janeiro.

Provavelmente, como já foi sugerido, esta mudança, que não parece ter resultado diretamente de qualquer iniciativa da coroa ou reforma por ela decretada, estava articulada com uma alteração da relação de forças entre os grupos mercantis e a nobreza da terra, desde meados dos setecentos, favorável aos primeiros. No caso particularmente bem estudado do Rio de Janeiro, ${ }^{52}$ essa evolução resultou em larga medida da crescente prosperidade comercial do centro-sul, que reforçou os grupos ligado ao capital mercantil e acentuou o declínio ou até extinção dos "conquistadores". O destino da descendência dos negociantes não deixou de ser porém, em muitos casos, a aquisição de bens fundiários e até a aliança com a velha nobreza da terra, embora também pudesse passar pelo investimento numa carreira judicial ou burocrática ou no regresso ao reino.

Acresce que a circulação no Atlântico era parte integrante dos percursos de vida, não só daqueles que chegavam a se integrar nos grupos mercantis das várias praças do Brasil, mas ainda naqueles que alcançavam o estatuto de negociante grossista e matriculado da praça de Lisboa, conforme demonstrou Jorge Pedreira, e em aberto contraste com o predomínio cristão-novo no século XVII. ${ }^{53}$ Para mais, a circulação no Atlântico alcançava patamares muito

${ }^{51}$ Cf. Fábio Khun, "O poder na aldeia: as elites locais na fronteira da América portuguesa. Viamão (1763-1773)", Revista do Instituto Histórico Geográfico do Rio Grande do Sul, n. 141, 2006/2007, p. 46-49.

${ }^{52}$ Cf. João Fragoso, Carla M. C. Almeida e Antonio C. Jucá de Sampaio (org.), Conquistadores e negociantes. Histórias de elites no Antigo Regime nos trópicos. América lusa, séculos XVI a XVIII, Rio de Janeiro, Civilização Brasileira, 2007, p. 25-29; João Fragoso, “Fidalgos e parentes de pretos: notas sobre a nobreza principal da terra do Rio de Janeiro (1600-1750)”, in: João Fragoso et al., Conquistadores e negociantes..., op. cit., p.34-120; António Carlos Jucá de Sampaio, "Famílias e negócios: a formação da comunidade mercantil carioca na primeira metade do setecentos", in: idem, p. 226-264; João Fragoso, Homens de grossa aventura. Acumulação e hierarquia na praça mercantil do Rio de Janeiro 1790-1830, 2. ed., Rio de Janeiro, Civilização Brasileira, 1998; idem e Manolo Florentino, O arcaísmo como projeto. Mercado atlântico, sociedade agrária e elite mercantil no Rio de Janeiro, c.1790- c.1840, 3. ed., Rio de Janeiro, Civilização Brasileira, 1998.

${ }^{53}$ Cf. Jorge M. Pedreira, Os homens do negócio da praça de Lisboa de Pombal ao vintismo (1755-1822). Diferenciação, reprodução e identificação de um grupo social, dis. dout. mimeo., Lisboa, Faculdade de Ciências Sociais e Humanas, 1995. 
elevados, incluindo significativas remessas, designadamente de ouro, do Brasil para o reino. ${ }^{54}$

Uma vez que os percursos eram bem-sucedidos nas atividades mercantis, os negociantes e os seus filhos podiam ter destinos diversos (incluindo o regresso ao reino, ou a frequência da Universidade de Coimbra, para estes últimos), mas de uma forma geral parece registrar-se uma tendência para serem absorvidos pelas elites agrária e escravista estabelecidas, particularmente na segunda metade do século XVIII. É o que se verifica em parte no Rio, conforme sugeriu João Fragoso, mas também, entre outros, no caso do Recife. Este último é particularmente significativo, pois a câmara surgira no início do século, como é bem sabido, do enfrentamento entre reinóis/negociantes e naturais/ senhores de engenho, ${ }^{55}$ essa dupla polarização, de acordo com recente estudo, tende a atenuar-se ao longo do século, no interior de uma elite plural mas cuja identidade se reforçava, entre outros fatores, pelos laços de parentesco e por uma polarização face a uma população majoritária de escravos e mestiços. ${ }^{56}$ De resto, o acesso de naturais do Brasil a distinções como as familiaturas do Santo Ofício e os hábitos das ordens militares cresceu claramente em termos absolutos e proporcionais no século XVIII ${ }^{57}$ Em termos relativos, parece que foram conferidos mais hábitos das ordens no Brasil setecentista do que aqueles de todas as Américas espanholas na mesma época. ${ }^{58}$

Em conclusão, tudo parece sugerir que a fratura identitária entre reinóis e naturais da América portuguesa era bem pouco pronunciada em 1808. Os processos sociais e institucionais antes descritos não podem deixar de ter pesado nessa evolução, que contrasta com algumas presunções há tempos muito difundidas. As clivagens políticas e identitárias das décadas subsequentes foram em parte geradas pelos contextos específicos destas e não parecem ter decorrido linearmente de diferenças de naturalidade.

\footnotetext{
${ }^{54}$ Cf. Maria Manuela Rocha e Leonor Freire Costa, "Remessas de ouro brasileiro: organização mercantil e problemas de agência em meados do século XVIII", Análise Social, v. XLII (1. ${ }^{\circ}$ ), 2007 (n. 182), p. 77-98.

${ }^{55} \mathrm{Cf}$. Evaldo Cabral de Mello, op. cit.

${ }^{56}$ Cf. George F. Cabral de Souza, op. cit., p. 617-618.

${ }^{57}$ Segundo Fernanda Olival, Honra, mercê e venalidade: as Ordens Militares e o Estado Moderno, Lisboa, Estar, 2001, p. 458-459 e Daniela Buono Calainho, Agentes da Fé. Familiares da Inquisição no Brasil Colonial, Bauru, São Paulo, Edusc, 2006, p. 69-110 e 176-186.

${ }^{58}$ Cf. Juan Carlos Caravaglia e Juan Marchena, América Latina..., op. cit., p.301.
} 